\begin{tabular}{|c|c|c|}
\hline $\begin{array}{l}\text { ISSN 2525-4812 (versão online) } \\
\text { ISSN 2238-7641 (versão impressa) } \\
\text { http://www.revistaterceiramargem.com/ } \\
\text { index.php/terceiramargem/index }\end{array}$ & $\begin{array}{c}\text { Recebido em: 30/6/2019 } \\
\text { Aprovado em: 23/1/2020 } \\
\text { Período de publicação: jan./jun., } 2020\end{array}$ & $\begin{array}{c}\text { Revista Terceira } \\
\text { Margem Amazônia } \\
(\text { v. } 6 \cdot \mathrm{n} .14 \cdot \text { Jan./Jun. } 2020)\end{array}$ \\
\hline
\end{tabular}

Como citar o artigo:

AQUINO, A. S. de; SILVA, R. O. Acordos de pesca no Amazonas: instrumento de gestão e participação social. Revista Terceira Margem Amazônia, v. 6, n. 14, p. 17-29, 2020. DOI: http://dx.doi.org/10.36882/2525-4812.2020v6i14p17-29

\title{
ACORDOS DE PESCA NO AMAZONAS: INSTRUMENTO DE GESTÃO E PARTICIPAÇÃO SOCIAL
}

\author{
Alzenilson Santos de Aquino ${ }^{l}$ \\ Regina Oliveira da Silva ${ }^{2}$
}

\begin{abstract}
Resumo: A ausência de políticas públicas que regulamentem as atividades pesqueiras ocasionou, na Amazônia, conflitos entre pescadores e moradores de comunidades. Os acordos de pesca (APs) são ferramentas de participação social. Foram estudados acordos de pesca em dois municípios do Amazonas, por meio da abordagem qualitativa, com consultas a pescadores e instituições. O estado do Amazonas possui 70 acordos de pesca, distribuídos em 35 municípios. Os municípios estudados, Boa Vista do Ramos e Parintins, possuem respectivamente três e um acordos de pesca. Os acordos de pesca são considerados pelos pescadores como positivos, geradores de benefícios que recuperam estoques pesqueiros, melhoram a renda e promovem redução de conflitos. No entanto, para os pescadores e instituições, é a ausência do poder público que contribui para que os acordos não funcionem devidamente, levando à perda de recursos naturais, da biodiversidade, assim como a diminuição da atividade pesqueira devido à escassez do pescado na região.
\end{abstract}

Palavras-chave: população ribeirinha de várzea, recursos pesqueiros, Amazônia, conflitos.

\section{FISHING AGREEMENTS IN AMAZONAS: INSTRUMENT OF MANAGEMENT AND SOCIAL PARTICIPATION}

\begin{abstract}
The absence of public policies that regulate fishing activities has led to numerous conflicts in the Amazon between fishermen and community dwellers. The Fisheries Agreements (PA) of two municipalities were studied through a qualitative approach, with interviews with fishermen and institutions. The State of Amazonas has 70 Fisheries Agreements, distributed in 35 municipalities. The municipalities studied, Boa Vista do Ramos and Parintins, have three and one Fisheries Agreements, respectively. Fisheries Agreements are considered by fishermen to be positive, benefit-generating, which recover fish stocks, improve incomes and promote conflict reduction. However, for fishermen and institutions it is the absence of public authority that contributes to the agreements to not functioning properly leading to the loss of natural resources, biodiversity leading to the reduction of fishing activity due to the scarcity of fish in the region.
\end{abstract}

Key words: varzea lake, riverine population, fishery resources, conflicts.

\footnotetext{
${ }^{1}$ Biólogo, M. Sc. em Gestão de Áreas Protegidas na Amazônia, subsecretário municipal do meio ambiente do município de Parintins, Parintins, AM. E-mail: alzenilson.aquino@gmail.com

${ }^{2}$ Bióloga, D. Sc. em Desenvolvimento Sustentável, pesquisadora do Museu Paraense Emílio Goeldi. Belém, PA. E-mail: oliveira@museu-goeldi.br
} 


\section{Introdução}

As várzeas são planícies alagáveis pelas águas ricas em sedimentos dos rios. Todo ano, as águas do Rio Amazonas e de seus afluentes transbordam as margens de suas extensas seções inferiores e inundam uma área imensa, estimada em 64.591.108 hectares, sendo que essas várzeas são as mais extensas do planeta. Pesquisadores catalogaram centenas de espécies de peixes e aves, uma grande variedade de mamíferos, répteis e anfíbios, além de uma diversidade excepcional de árvores, que vivem ou dependem desse ecossistema único (AYRES, 1994; BORGES et al., 2004; GOULDING, 1980; HENDERSON; ROBERTSON, 1999). Do ponto de vista das populações ribeirinhas amazônicas envolvidas na gestão dos recursos, a paisagem das várzeas tem quatro componentes principais: os canais principais dos rios; os diques naturais que margeiam esses canais; os lagos permanentes de várzea que ocupam grande parte do interior das várzeas; e pastagens sazonalmente inundadas que cobrem a zona de transição entre diques e lagos.

A pesca é uma das atividades humanas mais importantes na Amazônia, constituindo-se em fonte de alimento, comércio, renda e lazer para grande parte de sua população, especialmente as que residem nas margens dos rios de grande e médio porte (SANTOS, 2005). A pesca intensiva, nas várzeas amazônicas, gera conflitos em duas dimensões complementares. A primeira é relacionada à sustentabilidade dos recursos, refletindo a contradição entre economia e ecologia. A segunda expressa os interesses e perspectivas distintos entre os stakeholders, da população local em relação aos pescadores de fora que têm acesso ao recurso. Neste contexto, formas tradicionais de gerenciamento dos recursos comuns se tornam vulneráveis. Isso demanda novas e mais eficientes formas de gerenciamento, como os acordos de pesca (OVIEDO et al., 2015).

Reservas de pesca foram, por algum tempo, consideradas para a Amazônia. Bayley e Petrere (1989), Petrere (1990) e Ribeiro e Petrere (1990) já haviam sugerido o controle de pescarias em áreas remotas, o estabelecimento de áreas controladas, e a criação de reservas controladas poderia ser uma maneira efetiva de proteger e manejar as espécies assim como reduzir pressão de pesca.

Os modelos de gestão participativa que evoluíram nas várzeas da Amazônia resultam em iniciativas locais, governos, universidades, ONGs e agências internacionais de financiamento (OVIEDO; CROSSA, 2011). O manejo comunitário tem evoluído para complexos acordos de pesca resultantes dos interesses das comunidades. Tais acordos se constituíram para a proteção dos direitos de exploração dos membros da comunidade e, aparentemente, não são motivados por razões ambientais (RUFFINO; ISAAC, 1999).

Os acordos de pesca são estratégia de administração do recurso pesqueiro que reúne um número significativo de comunidades de pescadores e define normas específicas, regulando assim a pesca de acordo com os interesses da população local e com a preservação dos estoques pesqueiros (CARDOSO et al., 2018). Esses acordos podem estabelecer zonas de pesca, proibindo-a em determinados locais tidos como criadouros naturais, além de poder definir áreas de preservação temporária e áreas de conservação. Atualmente são acompanhados por técnicos do estado, dos municípios, pelas entidades de classe, como colônias e sindicatos de pescadores, sendo comuns ao longo das várzeas da Amazônia e atendem as regras especificadas na Instrução Normativa $n^{\circ}$ 29, publicada pelo Instituto Brasileiro do Meio Ambiente e dos Recursos Naturais Renováveis (Ibama) em 31/12/2002. Em 2011, a Lei Complementar nº 140/2011 da Constituição Federal, 
nos dispositivos constitucionais relativos à gestão ambiental, trouxe novas mudanças, dessa vez no arranjo de competências entre União, estados e municípios. No mesmo ano, a Secretaria de Estado do Meio Ambiente e Desenvolvimento Sustentável do Amazonas estabeleceu critérios e procedimentos para regulamentação de acordos de pesca pelo estado, por meio da Instrução Normativa $\mathrm{n}^{\mathrm{o}} 003 / 2011$.

O objetivo deste trabalho foi analisar os acordos de pesca como instrumento de gestão no estado do Amazonas tomando como estudo os acordos de pesca dos municípios de Boa Vista do Ramos e de Parintins. Além disso categorizaram-se esses acordos no estado do Amazonas.

\section{Metodologia de Pesquisa}

O Território Rural do Baixo Amazonas é constituído pelos municípios de Urucará, São Sebastião do Uatumã, Barreirinha, Nhamundá, Boa Vista do Ramos e Maués. O clima predominante é o equatorial úmido e chuvoso, com variações térmicas de $27{ }^{\circ} \mathrm{C}$ a $30{ }^{\circ} \mathrm{C}$ (PLANO..., 2010). Nesse território foram estudados os acordos de pesca dos municípios de Boa Vista do Ramos e Parintins (Figura 1).

Figura 1. Imagem de satélite localizando os municípios de Parintins, Nhamundá e Boa Vista do Ramos, no estado do Amazonas.

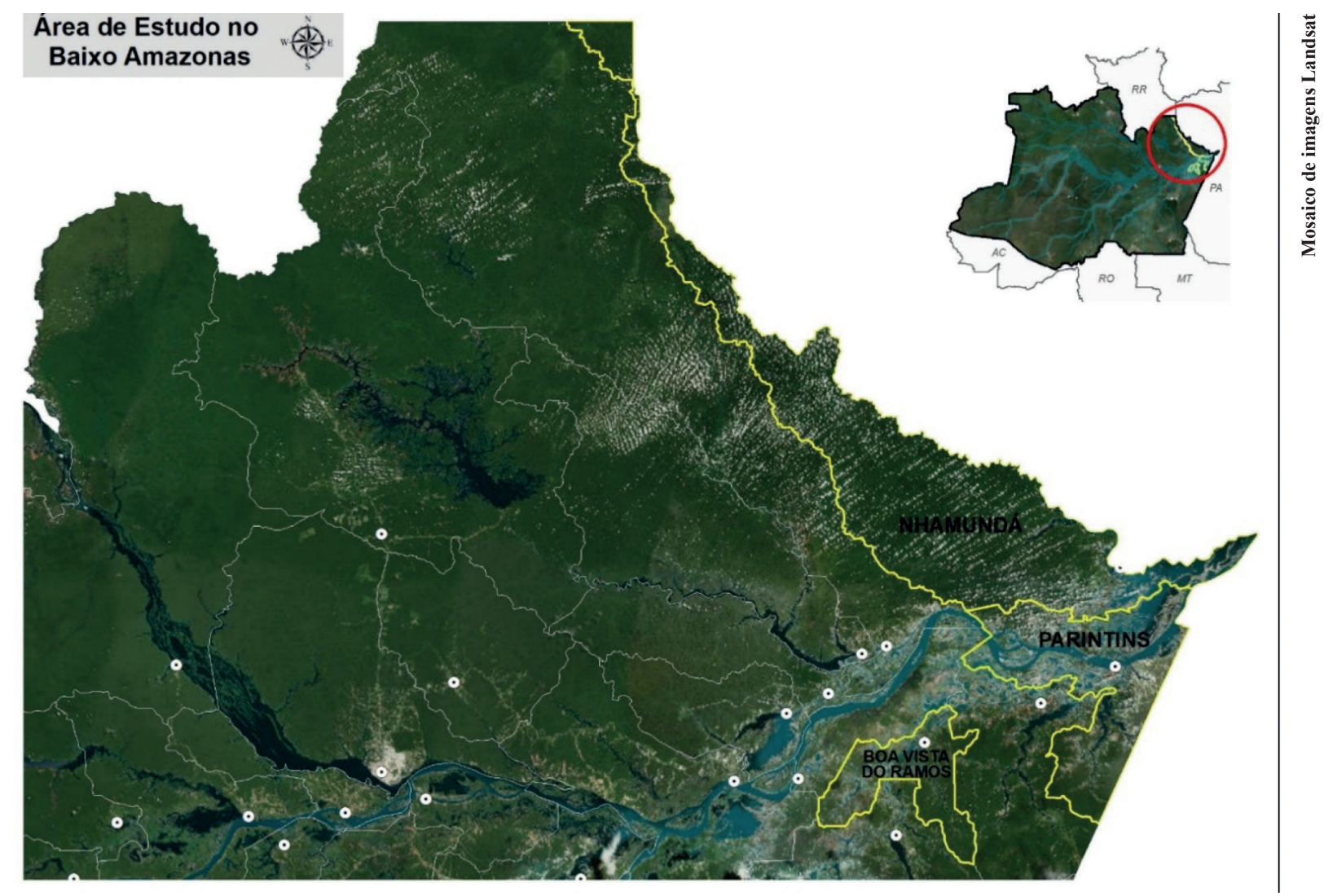


A fim de descrever os processos dos acordos de pesca nas regiões estudadas utilizou-se o método de Estudo de Caso, considerando que esse é um procedimento metodológico que enfatiza entendimentos contextuais (YIN, 2005). Esta pesquisa considerou ainda a percepção dos envolvidos com os acordos de pesca. Assim, foram consideradas as falas de pescadores e representantes de instituições envolvidas nesses acordos (50\% eram governamentais e 50\% da sociedade civil), conferindo à pesquisa caráter qualitativo. A coleta de dados nos municípios de Boa Vista do Ramos e Parintins foi realizada na sede municipal. Cabe destacar que, para este estudo, se trabalhou com métodos de categorização das respostas obtidas nas consultas realizadas, como forma de análise e compreensão, relacionando-as ao tema em questão. "Isto porque a análise de conteúdo se faz pela prática" (BARDIN, 2009, p. 51). Evidencia-se que os resultados obtidos serão repassados às comunidades onde há acordos de pesca e às instituições visitadas, sob forma de pôster e impressa.

\section{Resultados e Discussão}

\section{Acordo de Pesca no Estado do Amazonas}

As primeiras medidas de regulamentação das atividades pesqueiras na Amazônia foram implementadas primeiramente por meio da Superintendência para o Desenvolvimento da Pesca (Sudepe), criada em 1962 e extinta em 1988, e depois pelo Ibama (FREITAS; RIVAS, 2002), sem a necessidade de serem legalizadas ou regulamentadas. Com a publicação pelo Ibama da IN 29 em 2002, os acordos de pesca foram reconhecidos como instrumento de ordenamento pesqueiro que estabelecia critérios para a regulamentação deles (ALMEIDA, 2006). No entanto, a situação foi-se alterando e os conflitos de pesca aumentaram, e os acordos de pesca formais surgem com o propósito de mitigar os conflitos e estabilizar ou reduzir a pressão sobre os recursos pesqueiros locais.

Atualmente o estado do Amazonas possui 70 acordos de pesca, distribuídos em 35 municípios, elaborados entre 1995 e 2017 e regulamentados por meio de instrução normativa ou portaria do governo federal, pelo Ibama ou Ministério do Meio Ambiente (MMA) e pelo governo do estado, por meio da Secretaria de Estado do Meio Ambiente (Sema)/Instituto de Proteção Ambiental do Amazonas (Ipaam), ou de forma conjunta (Figura 2).

No estado do Amazonas, o governo federal regulamentou 45 acordos de pesca distribuídos em 26 municípios, os quais foram implementados entre 1995 e 2009 . Vale ressaltar que o acordo de pesca de Barcelos com IN n ${ }^{\circ}$ 002/2004 foi legalizado de forma conjunta entre o governo federal e o governo estadual. O governo do estado do Amazonas regulamentou 24 acordos de pesca no período de 2005 a 2017, distribuídos em 23 municípios.

Dos 70 acordos de pesca no estado do Amazonas, sete são intermunicipais, envolvendo dois ou três municípios. Destes, dois são regulamentados pelo governo do estado do Amazonas, via Sema e Ipaam, e cinco são regulamentados pelo Ibama. 
Figura 2. Mapa dos municípios que possuem acordos de pesca no estado do Amazonas.

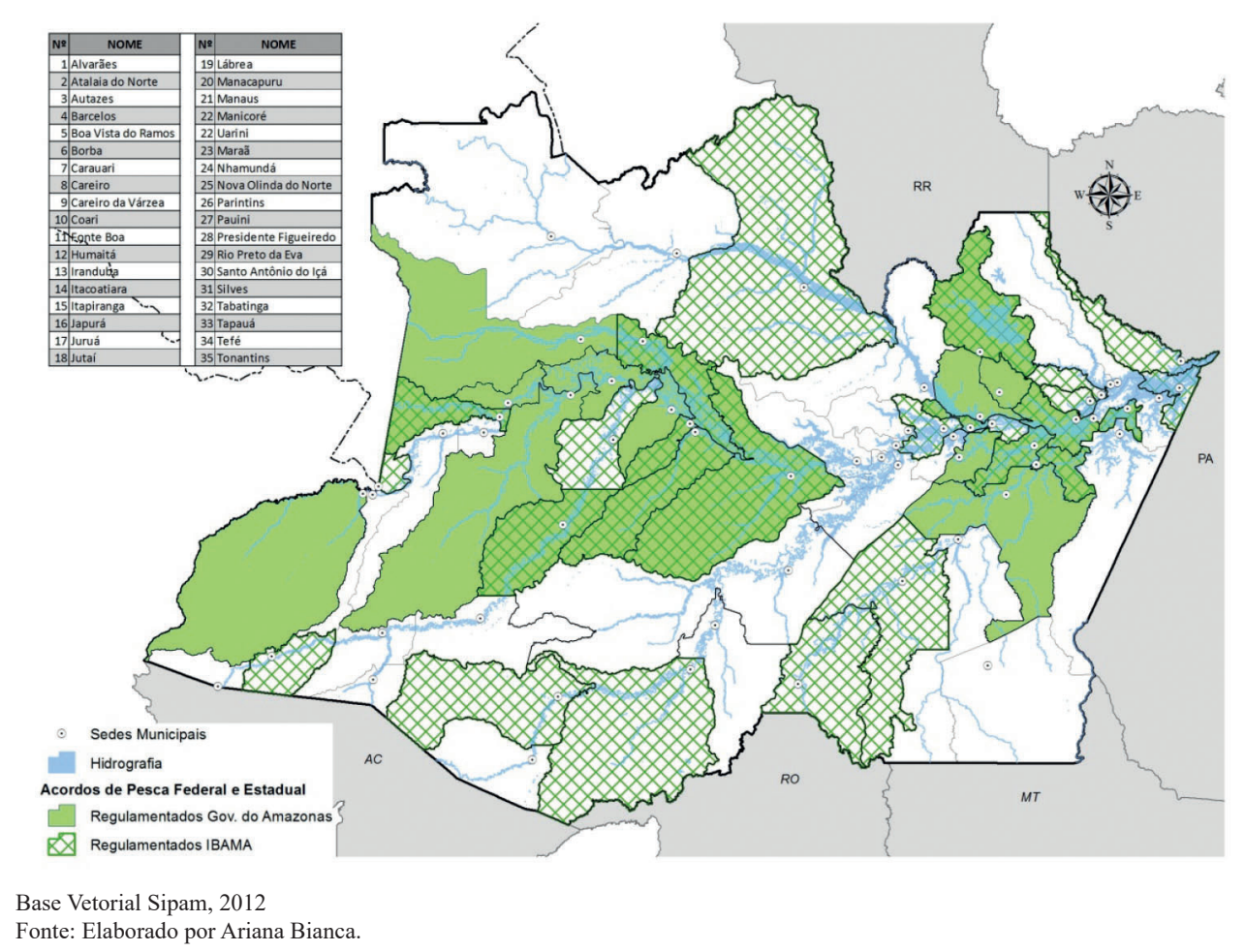

No Amazonas, a regulamentação dos acordos de pesca pelo Ibama iniciou-se em 1995, mas é na década de 2000 que se observa o maior número de acordos regulamentados, totalizando 29. A publicação da IN 29, que regulamentou os acordos de pesca comunitários, pode ter incentivado e dado segurança às comunidades ribeirinhas em regulamentar seus acordos informais, o que pode justificar o número de acordos de pesca regulamentados nessa década (Figura 3).

Figura 3. Número de acordos de pesca regulamentados por órgãos federais e estaduais no período de 1990 a 2010.

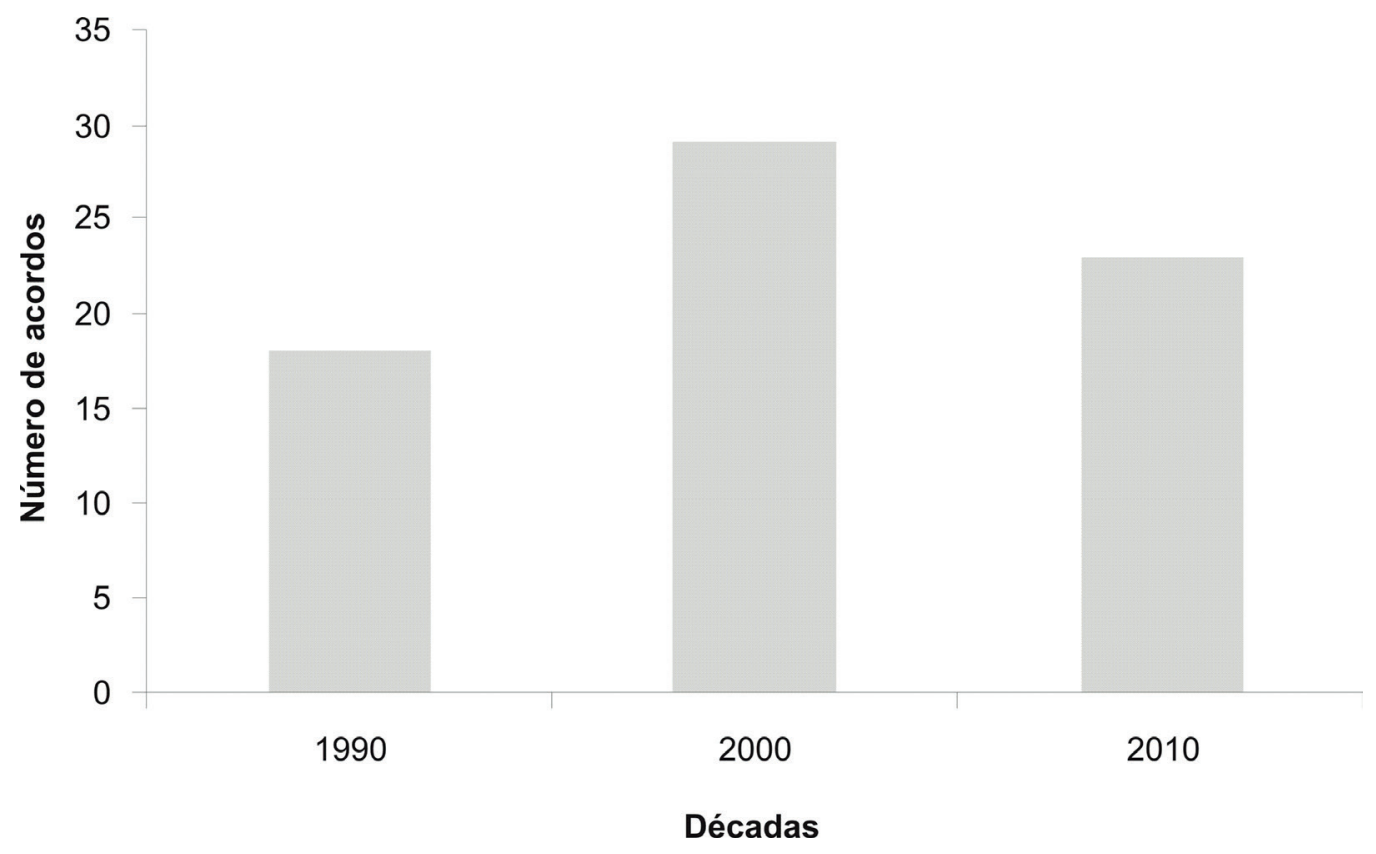

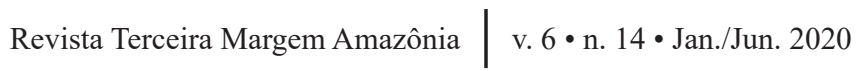


Dentre os acordos de pesca existentes no Amazonas, 23 definem que a fiscalização deve ser realizada pelo Sistema Nacional do Meio Ambiente e por mutirões ambientais; 2 acordos de pesca indicam que as fiscalizações podem ser realizadas pelos agentes ambientais voluntários; e em 23 acordos de pesca os lagos foram categorizados para procriação (não permite a pesca), manutenção (permitida a pesca de subsistência) e comercial (permitida a pesca para comercialização); em 22 acordos de pesca há previsão para o manejo do pirarucu (Arapaima gigas); e 38 acordos não definem como será realizada a fiscalização. Não se obteve documentação necessária para a análise de 7 acordos.

\section{Acordos de pesca nos municípios de Boa Vista do Ramos e Parintins}

As atividades dos acordos de pesca de Boa Vista do Ramos, AM, iniciaram-se em 2001. $\mathrm{O}$ município possui três acordos de pesca. Estes foram instituídos pelo Ibama (Portarias $\mathrm{n}^{\mathrm{o}} 10 \mathrm{e}$ $n^{\circ} 11$ de março/2003) e pela SDS (Instrução Normativa $n^{\circ} 002$ de junho/2011). Os acordos estão sendo aplicados na região dos Lagos, atendendo a quatro comunidades; na região do Rio Urubu, abrangendo seis comunidades; e a terceira região compreende o complexo de lagos da comunidade São Tomé. A Colônia de Pescadores Z-15 é parceira das comunidades atendidas com acordos de pesca, tendo como missão monitorar e avaliar as regras estabelecidas. Ressalta-se que a temporalidade entre os acordos supracitados deve ser considerada, visto que, em 2003, tais instrumentos objetivavam conter as invasões externas e garantir os territórios de pesca às comunidades locais. Já nos acordos estabelecidos pelo estado, há a inserção de conhecimento local e resultados de pesquisa sobre espécies e seu manejo.

Foram consultados dez pescadores entre homens e mulheres, com média de idade entre 27 e 72 anos, escolaridade predominante de ensino fundamental incompleto. Todos os consultados afirmaram que conhecem os acordos. Dentre as ações de que participaram para a elaboração dos acordos, destacaram: reuniões comunitárias e intercomunitárias, assembleia geral, elaboração das regras, escolha dos lagos e suas categorias. Todos responderam positivamente sobre a sua importância, instigados a explicar o porquê, as respostas foram categorizadas. Para 90\%, os aspectos ambientais foram importantes ao argumentarem que "aumentou o pescado, aumentou o tamanho dos peixes, apareceu mais pirarucu". Os demais consultados consideraram aspectos econômicos ao se referirem à situação em que o esforço de trabalho e a renda obtida foram relevantes. No que se refere aos problemas enfrentados após a implementação dos acordos de pesca, 80\% dos consultados alegaram a descontinuidade da gestão, a ausência do poder público, as invasões de embarcações de outros estados, a falta de divulgação dos acordos e a falta da organização comunitária. Questionados se "é melhor com ou sem acordo de pesca e por quê", os consultados foram unânimes em afirmar que "é melhor" com o acordo e, nas explicações, ressaltaram que "os pescadores passavam menos tempo pescando e pegavam mais peixe".

No que se refere às instituições entrevistadas, quanto à sua atividade junto ao processo de discussão dos acordos de pesca em Boa Vista do Ramos, estas atuaram na mobilização das comunidades, participando da organização das reuniões e contribuindo com a elaboração das regras e as escolhas dos lagos para o manejo. A participação das instituições, seja ela governamental ou não governamental, no processo de elaboração dos acordos de pesca teve importante papel, o de informar e suprimir dúvidas dos pescadores e comunidades quanto ao que é permitido como regra 
do acordo, visando não ferir as leis vigentes. Para 100\% das instituições consultadas o acordo de pesca é um importante instrumento de gestão dos recursos pesqueiros na redução de conflitos e recuperação dos estoques pesqueiros. No entanto, segundo os consultados, com o passar dos anos, as regras vão deixando de ser cumpridas, principalmente pela falta de fiscalização do poder público. Destaca-se que as instituições também veem o poder público como "mola mestre" para o funcionamento dos acordos de pesca. As instituições consultadas também apontam para a necessidade da organização das comunidades e esperam que os acordos de pesca de Boa Vista do Ramos possam ser retomados e rediscutidos para o seu fortalecimento junto ao processo de manejo dos recursos pesqueiros.

Segundo Bocarde e Lima (2008), em Parintins, desde a década de 1970, os acordos de pesca eram firmados entre as comunidades usuárias de determinado lago e registrados em ata. Em alguns casos, esses acordos foram validados pelo Ministério Público, por meio da emissão de um documento chamado "Termo de Conciliação". Foi o caso do Lago do Comprido (região do Paraná de Parintins), Lago da Benedita (região do Mocambo/Cabury) e Lago do Zé Açu (região do Zé Açu).

Parintins possui apenas um acordo regulamentado. Trata-se do acordo de pesca da região do Macuricanã. Essa região faz parte da área de proteção ambiental (APA) de Nhamundá, totalizando sete comunidades.

$\mathrm{O}$ acordo de pesca dessa região é regulamentado pela Instrução Normativa do Ibama $\mathrm{n}^{\mathrm{o}}$ 113, de 23 de agosto de 2006. Essa IN estabelece categorias de manejo para os lagos, poços, igarapés e baixas no complexo lacustre de Macuricanã, quais sejam: áreas de procriação, manutenção e uso comercial. Importante destacar que os pescadores e moradores das comunidades que participaram do processo de construção do acordo de pesca Macuricanã receberam capacitações básicas em geoprocessamento. Essas capacitações foram ministradas pelos técnicos do ProVárzea/Ibama, com o objetivo de envolver os participantes e aproveitar sua vivência desses ambientes. Estes participaram in loco do georreferenciamento de todos os lagos que hoje fazem parte do acordo. O acordo de pesca de Parintins envolve 94 lagos, dos quais 25 são comerciais, 45 são lagos de manutenção e 24 de procriações.

Essa região, de acordo com o Boletim Estatística Pesqueira do Amazonas e Pará (IBAMA, 2002), corresponde a 59\% da produção pesqueira em Parintins. Ainda de acordo com os dados da estatística pesqueira do ProVárzea, a produção do "Setor Macuricanã" (termo da estatística pesqueira para definir uma região de pesca) apresentou redução de produção de pescado nos últimos anos: 1.016 t em 2001; 694 t em 2002; 527 t em 2003; e 288 t em 2004. Motivos estes que incrementaram a elaboração do acordo em Parintins.

Foram consultados dez pescadores, entre homens e mulheres, com média de idade entre 39 e 60 anos, com escolaridade predominante de ensino fundamental incompleto. No que se refere à participação dos consultados nas discussões de elaboração do acordo de pesca, $20 \%$ afirmaram não ter participado, enquanto $80 \%$ participaram do processo. No entanto, todos os consultados afirmaram ter conhecimento do processo. Dentre as ações para a elaboração do acordo de pesca, os entrevistados destacaram: reuniões comunitárias e intercomunitárias, assembleias gerais, elaboração das regras, escolha dos lagos e suas categorias e das audiências públicas. 
Questionados sobre o que pensam do acordo de pesca, 100\% responderam positivamente, instigados a explicar o porquê; as respostas obtidas foram categorizadas. No que se refere ao aspecto ambiental, $100 \%$ dos consultados argumentaram que "aumentou o pescado"; "pesca mais", referindo-se à quantidade de peixe nos lagos. Outros consideraram aspectos econômicos ao falarem que "melhorou a renda do pescador". Houve respostas que consideram o aspecto social do acordo de pesca, ao afirmarem que houve "redução dos conflitos". Para os pescadores, o acordo de pesca é um instrumento importante para a gestão pesqueira, tanto para a recuperação do estoque quanto para a melhoria da renda. Entretanto, quando questionados sobre problemas enfrentados ao terem um acordo de pesca, estes citaram que a "diminuição do estoque pesqueiro, aumento das invasões e principalmente a redução da renda" comprometem o funcionamento do acordo. A falta de fiscalização, segundo os pescadores, é o principal entrave para o funcionamento do acordo. Outras dificuldades foram relatadas por $70 \%$ dos consultados, para eles a falta de infraestrutura e de insumos (flutuantes, lanchas e combustível) dificulta o cumprimento das regras.

Em Parintins, 20\% dos pescadores consultados relataram a pecuária como atividade prejudicial ao acordo de pesca. Para eles a criação de bubalinos destrói a vegetação, tanto de mata ciliar como as macrófitas, além de provocar o assoreamento de lagos e igarapés.

Questionados se "é melhor com ou sem o acordo de pesca e por quê", os consultados foram unânimes ao afirmar que "é melhor com o acordo", e as explicações ressaltaram que "o pescador passa menos tempo pescando, pega mais peixe, pois há redução das invasões". Salienta-se que a preferência pelo acordo de pesca está diretamente ligada ao aumento da quantidade do pescado e à redução do tempo de permanência do pescador no lago, o que reduz seu esforço de coleta e os conflitos. Além disso, alguns destacam a recuperação do estoque e, automaticamente, a melhoria da renda do pescador.

Quando instigados a responder à pergunta "O que você mudaria do acordo de pesca e por quê?”, as respostas foram agrupadas em aspectos ambientais e políticos de ação (Tabela 1).

Tabela 1. Sugestões dos pescadores consultados para mudanças no acordo de pesca. Parintins, AM.

\begin{tabular}{cl}
\multicolumn{1}{c}{ Ambiental } & \multicolumn{1}{c}{ Política de ação } \\
\hline \multicolumn{1}{c}{ Mudar categorias de lagos } & Melhorar a fiscalização \\
\hline Indicar novos lagos para acordos de pesca & Prever infraestrutura (flutuante e lancha) \\
\multirow{2}{*}{ Estudar a capacidade de suporte da pecuária na região } & $\begin{array}{l}\text { Retornar com o Programa dos Agentes } \\
\text { Ambientais Voluntários } \\
\text { Rever as regras dos apetrechos de pesca } \\
\text { Rever quantidade de pescado permitida }\end{array}$ \\
\end{tabular}

A fiscalização é um fator-chave nas respostas dos pescadores, e estes detêm conhecimentos quanto às regras e às categorias dos lagos, demonstrada na proposição de mudanças sugerindo o seu conhecimento sobre a biologia local. A pecuária também aparece como preocupação que deve ser tratada no âmbito do acordo de pesca, já que os participantes relacionaram a destruição da mata ciliar e o assoreamento dos lagos com a quantidade de gado bubalino na região.

Quanto às instituições consultadas junto ao processo de discussão do acordo de pesca em Parintins, estas afirmaram que dispuseram de tempo e pessoal na mobilização das comunidades, 
participaram da organização das reuniões, das assembleias e contribuíram com as regras e as escolhas dos lagos para o acordo, além de terem participado do monitoramento do referido instrumento e atuado na fiscalização por um período de tempo.

A participação das instituições, tanto governamentais quanto da sociedade civil, foi importante no processo de elaboração do acordo de pesca em Parintins, pois contribuíram no repasse de informações, minimizando as dúvidas dos pescadores e comunitários quanto ao que é plausível de estar como regra do acordo, a fim de não ferir as leis vigentes. Entre os representantes das instituições consultadas, 100\% afirmam que o acordo de pesca é um instrumento de gestão dos recursos pesqueiros importante na redução de conflitos e recuperação dos estoques. Esse instrumento depende de parceria entre os pescadores, comunitários e o poder público para a sua efetividade. Segundo os representantes das instituições consultadas, a fiscalização deve ser constante para que o acordo atinja seus objetivos. Isso porque, segundo seus representantes, "no início, o acordo de pesca deu certo, melhorando a renda do pescador, aumentou à captura do pescado, reduzindo o tempo de pesca". Com o término do ProVárzea, houve um abandono por parte do poder público, reduzindo as fiscalizações, e, consequentemente, houve o retorno das invasões, causando novamente conflitos. De acordo com os consultados há a necessidade de organização das comunidades, e uma das maneiras citadas para fazê-lo foi "trabalhando a educação ambiental para fortalecê-los, visando garantir o sucesso do acordo de pesca". Ainda segundo os representantes das instituições, a revisão das categorias dos lagos de acordo com sua função ambiental e a inserção do manejo do pirarucu (Arapaima gigas) e tambaqui (Colossoma macropomum) no referido instrumento deve ser considerada.

\section{Categorização dos acordos de pesca de Boa Vista do Ramos e Parintins no estado do Amazonas}

O levantamento dos acordos de pesca nos municípios de Boa Vista do Ramos e Parintins permitiu uma análise das regras dos acordos e sua categorização conforme as suas prioridades (Tabela 2).

A maioria desses acordos foi estabelecida com o objetivo de salvaguardar os estoques pesqueiros para as necessidades de subsistência, por meio da restrição da pesca comercial. Muitos acordos também estabelecem limites de captura por dia ou limites de capacidade dos barcos que têm acesso aos lagos.

Observa-se que, para os pescadores, o acordo de pesca é um instrumento importante para a gestão pesqueira e tem papel relevante na recuperação do estoque pesqueiro, melhorando assim a qualidade de vida de todos onde o acordo prevalece.

Castro e Mcgrath (2001) afirmam que, além das regras adotadas no manejo, devem ser consideradas as características dos grupos de usuários e dos ambientes de pesca. Almeida (2006), em estudos de avaliação dos acordos de pesca na região do Baixo Amazonas, verificou que a produtividade aumentou nos regimes de manejo comunitário de pesca, proporcionando benefícios às comunidades. Porém, os resultados sugerem, segundo o autor, que esses benefícios são conseguidos pela exclusão de pescadores comerciais itinerantes, ou seja, mitigação de conflitos. 
Tabela 2. Categorização das regras dos acordos de pesca de Boa Vista do Ramos e Parintins, AM.

\begin{tabular}{|c|c|c|c|c|}
\hline Categoria & $\begin{array}{c}\text { Portaria } \\
\text { n }^{\circ} 10 / 2003 \\
\text { Ibama }(\mathrm{BVR}) *\end{array}$ & $\begin{array}{c}\text { Portaria } \mathrm{n}^{0} \\
11 / 2003 \\
\text { Ibama }(\mathrm{BVR}) *\end{array}$ & $\begin{array}{l}\text { IN n }{ }^{\circ} 02 / 2014 \\
\text { Sena (BVR) }\end{array}$ & $\begin{array}{l}\text { IN n }{ }^{\circ} 113 / 2006 \\
\text { Ibama (PIN)* }\end{array}$ \\
\hline $\begin{array}{l}\text { Ambiental } \\
\text { Identifica os ambientes onde ocorre o } \\
\text { Acordo de Pesca }\end{array}$ & $\mathrm{X}$ & $\mathrm{X}$ & $\mathrm{X}$ & $\mathrm{X}$ \\
\hline \multicolumn{5}{|l|}{ Controle } \\
\hline Limita o número de malhadeira & $\mathrm{X}$ & $\mathrm{X}$ & - & - \\
\hline $\begin{array}{l}\text { Limita o tamanho da malhadeira e da } \\
\text { malha }\end{array}$ & $\mathrm{X}$ & $\mathrm{X}$ & $\mathrm{X}$ & - \\
\hline $\begin{array}{l}\text { Limita a distância de uma malhadeira } \\
\text { e outra }\end{array}$ & $\mathrm{X}$ & $\mathrm{X}$ & - & - \\
\hline $\begin{array}{l}\text { Limita a quantidade de pescado a ser } \\
\text { capturado }\end{array}$ & $\mathrm{X}$ & $\mathrm{X}$ & $\mathrm{X}$ & $\mathrm{X}$ \\
\hline Proíbe a captura de espécies & - & - & $\mathrm{X}$ & - \\
\hline Prever a avaliação do acordo & - & - & $\mathrm{X}$ & - \\
\hline Limita embarcação & - & - & - & $\mathrm{X}$ \\
\hline Prever fiscalização & $\mathrm{X}$ & $\mathrm{X}$ & $\mathrm{X}$ & $\mathrm{X}$ \\
\hline Categorizar os lagos & - & - & $\mathrm{X}$ & $\mathrm{X}$ \\
\hline \multicolumn{5}{|l|}{ Econômico } \\
\hline Prever o manejo do pirarucu & - & - & $\mathrm{X}$ & - \\
\hline
\end{tabular}

*BVR - Boa Vista do Ramos; *PIN - Parintins.

Fonte: Dados da pesquisa.

Para Cerdeira (2009), as restrições contidas no acordo de pesca da região do Rio Urubu/ Boa Vista do Ramos (Portaria Ibama n $n^{\circ}$ 11/2003) são causadas pelas invasões de barcos geleiros no âmbito de pesca das comunidades. Essa forma de exclusão também foi verificada por Almeida (2006). Neste estudo, segundo os consultados, a maioria dos pescadores e comunitários cumpre o acordo de pesca, contudo há comunitários que não o fazem. Há relatos de que muitos deles possibilitam a entrada de barcos de pesca de outros municípios, não cumprindo os acordos estabelecidos.

Segundo Almeida et al. (2011), em estudo realizado na região do Baixo Amazonas com acordos de pesca, a respeito do percentual de membros da comunidade que cumprem os regulamentos estabelecidos pelos acordos, 70\% afirmaram que mais de 50\% das famílias estão em conformidade com as regras. De acordo com os representantes das instituições consultadas no processo de discussão dos acordos de pesca se faz necessária a participação de todos os envolvidos no setor pesqueiro e que estes sejam respeitados independentemente do segmento a que pertençam. É importante que cada grupo social deva ter a oportunidade de entender o processo e participar ativamente com sugestões. Destaca-se que esse processo de discussão é também um momento de negociação para que o acordo comporte a realidade local. Segundo Cerdeira (2009), em seu estudo sobre o acordo de pesca da região do Rio Urubu, em Boa Vista do Ramos, as partes envolvidas nas discussões e elaboração das regras estão claramente definidas: as comunidades locais, representando o interesse dos moradores da região, e a Colônia de Pescadores Z-15 do município, representando os pescadores comerciais. 
De acordo com Almeida et al. (2011), em estudos realizados no Baixo Amazonas, as famílias das comunidades recebem instruções sobre o acordo local estabelecido. Segundo os autores, em seu estudo, $85 \%$ responderam que sabiam quais eram as principais regras estabelecidas pelo instrumento. Uma quantidade menor de entrevistados (36\%) soube responder detalhes dos acordos, como o ano em que ele foi aprovado oficialmente, o que respalda a importância desse instrumento na vida das famílias que dependem dos recursos pesqueiros.

Cerdeira (2009) sugere que o acordo comunitário de pesca é um bom instrumento de gestão, desde que os cogestores estejam aptos para isso, ou seja, que tenham sua organização pautada no trabalho conjunto voltado para o bom manejo pesqueiro. Esses acordos podem preencher a lacuna deixada pelo poder público no controle dos conflitos e ordenamento da pesca, principalmente em nível local.

\section{Considerações e Recomendações}

Observa-se que, para os pescadores, o acordo de pesca é um instrumento importante para a gestão pesqueira e tem papel relevante na recuperação do estoque pesqueiro, melhorando assim a qualidade de vida dos pescadores e moradores onde os acordos prevalecem.

Os acordos de pesca avaliados tiveram o apoio de projetos institucionais como o IARA e o ProVárzea/Ibama, o que pode ter sido um facilitador para a implementação destes. Isso se deveu muito provavelmente à disponibilidade de recursos financeiros e à manutenção de equipes em campo, o que proporcionou uma participação mais efetiva dos comunitários.

O encerramento dos projetos, e sem que estes tenham se consolidado no âmbito das comunidades partícipes no que se refere a organização, fomentos ou parcerias com outras organizações, pode ter ocasionado um declínio nas atividades, sobretudo na fiscalização, fazendo com que as comunidades se sentissem abandonadas. A participação no processo de discussão dos acordos de pesca deve ser reforçada, uma vez que, colaborando na elaboração das regras, categorização dos lagos, etc., faz com que os participantes se sintam valorizados e comprometidos com o acordado.

Os acordos de pesca das duas regiões no estado do Amazonas em questão são conhecidos pelos comunitários, pescadores e pelas instituições que dele participam, sendo, portanto, um instrumento para gestão dos recursos pesqueiros. Contudo, esse instrumento carece de parcerias, entre as instâncias do poder público e da sociedade civil organizada, para o seu funcionamento.

É importante apontar que os acordos de pesca dos municípios de Boa Vista do Ramos e de Parintins, apesar de estarem vigentes, não estão sendo cumpridos na sua plenitude.

Nas comunidades ribeirinhas onde há acordos de pesca, este é percebido como um instrumento de gestão participativa. Os acordos de pesca influenciam diretamente o modo de vida e as práticas das atividades pesqueiras, sobretudo por contribuir com a redução dos conflitos, propiciar a melhoria da qualidade de vida dos pescadores a partir do aumento de sua renda e permitir a recuperação dos estoques pesqueiros, conservando a biodiversidade local.

Podemos afirmar que as comunidades possuem capacidade de conduzir sozinhas o acompanhamento, o monitoramento e a avaliação dos acordos de pesca, no entanto faz-se necessário 
que as políticas públicas voltadas ao cumprimento dos acordos sejam aplicadas. Além disso, há demanda comunitária de capacitação para tal empreita. O papel das instituições governamentais e não governamentais deve estar pautado no envolvimento e comprometimento dos objetivos dos acordos de pesca. Além disso, devem se comprometer com o empoderamento das comunidades e instituições de classe, assim como ampliar para a sociedade local a divulgação da importância desses espaços para as populações ribeirinhas. As comunidades devem tomar parte dos acordos de pesca, e não depender exclusivamente do poder público.

Recomenda-se, portanto, que a Secretaria de Estado do Meio Ambiente inclua em seus programas a revisão dos acordos de pesca estudados e que eles possam estar voltados para o manejo do pirarucu ou de outras espécies comerciais. As comunidades devem ser empoderadas para que possam, em futuro próximo, ser autônomas e gerir seus acordos de pesca, assim como realizar o monitoramento e avaliação destes.

Recomenda-se ainda uma revisão na proposta de agentes ambientais voluntários (AAV) para que estes possam contribuir no monitoramento e na avaliação dos acordos de pesca.

\section{Referências}

ALMEIDA. O. T. et al. Pescadores rurais de pequena escala e o co-manejo no Baixo Amazonas. Belém, PA: Núcleo de Altos Estudos Amazônicos, 2011. (Papers NAEA, 287).

ALMEIDA, O. T. Manejo da pesca na Amazônia Brasileira. São Paulo: Editora Petrópolis, 2006.

AYRES, D. L. A implantação de uma unidade de conservação em área de várzea: a experiência de Mamirauá. In: D'INCAO, M. A.; SILVEIRA, I. M. (Ed.). Amazônia e a crise da modernização. Belém, PA: Museu Paraense Emílio Goeldi, 1994. p. 403-409.

BARDIN, L. Análise de conteúdo. Lisboa, Portugal: Edições 70, LDA, 2009.

BAYLEY, P. B.; PETRERE, M. Amazon fisheries: assessment methods, current status and management points. In: DODGE, D. P. (Ed.). Proceedings of the International Large River Symposium. Canadian Special Publication of Fisheries and Aquatic Sciences, p. 385-398, 1989.

BOCARDE, F.; LIMA, N. Construindo acordos de pesca: experiências de gestão participativa em Parintins. Brasília, DF: Ibama, 2008.

BORGES, S. H. et al. Janelas para a biodiversidade no Parque Nacional do Jaú: uma estratégia para o estudo da biodiversidade na Amazônia. Manaus: Fundação Vitória Amazônica, 2004.

CARDOSO, M. C. et al. Pescadores artesanais, conflito de interesses e os recursos pesqueiros visto como capital natural crítico: o caso do Lago do Juá em Santarém, Pará. O Social em Questão, ano 21, n. 40, p. 309-332, jan./abr. 2018.

CASTRO, F.; MCGRATH, D. O manejo comunitário de lago na Amazônia. Parcerias Estratégicas, n. 12, p. 112-126, set. 2001.

CERDEIRA, R. G. Acordo de pesca como instrumento de gestão participativa na Amazônia. 2009. 133 f. Dissertação (Mestrado em Direito Ambiental) - Universidade do Estado do Amazonas, Manaus. 
FREITAS, C. E. C.; RIVAS, A. A. F. Peixe: a sustentabilidade de um recurso comum na Amazônia: In: FREITAS, C. E. C.; RIVAS, A. A. F. Amazônia: uma perspectiva interdisciplinar. Manaus: EDUA, 2002. p. 225-251.

GOULDING, M. The fishes and the forest: explorations in Amazonian Natural History. Berkeley: University of California Press, 1980. 280 p.

HENDERSON, P. A.; ROBERTSON, B. A. On structural complexity and fish diversity in an Amazonian Floodplain. In: PADOCH, C. et al. (Ed.). Várzea: diversity, development and conservation of Amazonia's whitewater floodplains. New York: New York Botanical Garden Press, 1999. p. 197-202.

IBAMA. Estatística pesqueira do Amazonas e Pará - 2001. Manaus, 2002.

OVIEDO, A. F. P. et al. Agora sob nova administração: acordos de pesca nas várzeas da Amazônia Brasileira. Ambiente \& Sociedade, v. 18, n. 4, p. 119-138, 2015.

OVIEDO, A. F. P.; CROSSA, M. N. Manejo do pirarucu - sustentabilidade nos lagos do Acre. Brasília, DF: WWF-Brasil, 2011. p. 67.

PETRERE, M. As comunidades humanas ribeirinhas da Amazônia e suas transformações sociais. In: FURTADO, L. G. (Ed.). IV Encontro de Ciências sociais e o mar no Brasil: populações humanas, rio e mares da Amazônia. Belém, PA: UFPA, 1990.

PLANO Territorial de Desenvolvimento Rural Sustentável do Baixo Amazonas. Estudo técnico. Manaus: Cáritas - Arquidiocesana de Manaus, 2010.

RIBEIRO, M. C. L. B.; PETRERE, M. Fisheries ecology and management the Jaraqui (Semaprochilodus taeniurus, S. insignis) in Central Amazonia. Regulated Rivers: Research and Management, p. 195-215, 1990.

RUFFINO, M. L.; ISAAC, V. J. The fisheries of the lower Amazon: questions of management and development. Acta Biologica Venezuelica, p. 37-46, 1999.

SANTOS, G. M.; SANTOS, A. C. M. Sustentabilidade da pesca na Amazônia. Estudos Avançados, p. 19-54, 2005.

YIN, R. K. Estudo de caso: planejamento e métodos. 3. ed. Porto Alegre: Bookman, 2005. 
